\title{
Nível de Dano Econômico de Brachiaria plantaginea NA CultuRA DE MiLho IRRIGADO ${ }^{1}$
}

\author{
Economic Weed Threshold (EWT) of Brachiaria plantaginea in Irrigated Corn Crop
}

\author{
VIDAL, R.A. ${ }^{2}$, SPADER, V. ${ }^{3}$, FLECK, N.G. ${ }^{2}$ e MEROTTO JR., A. ${ }^{3}$
}

\begin{abstract}
RESUMO - O nível de dano econômico (NDE) consiste na quantidade de plantas daninhas que causa impacto no rendimento de grãos da cultura que justifique o custo de seu controle. Os objetivos deste trabalho foram avaliar a possibilidade de utilizar experimentos de eficácia de herbicidas residuais para determinar o NDE, a partir do rendimento de grãos em relação à densidade de plantas de Brachiaria plantaginea (BRAPL) que emergem após o tratamento, e avaliar o impacto do preço da cultura e do custo do controle no NDE. A densidade de BRAPL foi determinada em um experimento no qual se realizaram tratamentos químicos que possibilitaram a emergência de diferentes quantidades de plantas e, em consequêencia, vários niveis de interferência sobre a cultura do milho. A avaliação da densidade foi feita aos 10, 20, 30, 40 e 50 dias após a emergência (DAE), de forma a abranger o período crítico de prevenção da interferência. Ao final do experimento foi avaliado o rendimento de grãos da cultura do milho. A resposta da regressão entre densidade de BRAPL e rendimento de grãos de milho ajustou curvas do tipo exponencial decrescente nas avaliações realizadas aos 10 e 20 DAE e curvas do tipo logístico (sigmoidal) aos 30, 40 e 50 DAE. O NDE de BRAPL em milho, com base na densidade determinada no início do período crítico de prevenção da interferência (20 DAE), considerando nível de produtividade de $10 \mathrm{t} \mathrm{ha}^{-1}$, variou entre 0,2 e 2,0 plantas $\mathrm{m}^{-2}$, dependendo do preço do milho e do custo do controle. O NDE determinado ao término do período crítico de interferência (50 DAE) correspondeu às densidades de BRAPL de 1,5 a 13 plantas $\mathrm{m}^{-2}$. Conclui-se que o NDE de BRAPL na cultura de milho pode ser estabelecido com dados de densidade desta espécie, determinados em experimentos para testes de herbicidas residuais. Assim, o NDE previsto será adequado para situações em que se deseja decidir por aplicações de herbicidas em pós-emergência em áreas onde foram aspergidos herbicidas residuais. Conclui-se, também, que o NDE de BRAPL em milho aumenta à medida que o preço da cultura diminui e o custo do controle aumenta e que o aumento do preço de grãos reduz o impacto do custo do controle de BRAPL no retorno econômico da cultura.
\end{abstract}

Palavras-chave: herbicidas residuais, metodologia de pesquisa, interferência, competição.

\begin{abstract}
Economic weed threshold (EWT) consists of the number of weeds impacting crop grain yield to justify the cost of their control. The objectives of this work were to evaluate the feasibility of using herbicide experiment results to establish EWT, based on regression between corn grain yield and Brachiaria plantaginea (BRAPL) density assessed on several occasions; and to evaluate crop price and weed control cost impact on EWT. BRAPL densities were determined by applying herbicide treatments allowing several levels of weed emergence and, consequently several levels of weed-crop interference. Weed density was evaluated at 10,20,30, 40 and 50 days after crop emergence (DAE) to cover the critical weed-crop competition period. Crop grain yield was determined at crop maturity. The results of the regression between BRAPL density and corn grain yield have adjusted exponential decay curves for assessments performed at 10 and 20 DAE and sigmoidal curves at 30, 40 and 5O DAE. EWT of BRAPL in corn, based on densities assessed at $20 \mathrm{DAE}$ and for $10 \mathrm{th} \mathrm{h}^{1}$ of grain yield, ranged from 0.2 and 2.0 plants $\mathrm{m}^{2}$, depending on crop price and weed control cost. EWT assessed at 5O DAE ranged between 1.5 and 13 plants $\mathrm{m}^{2}$. This work confirmed that weed densities increase with time, allowing to
\end{abstract}

Recebido para publicação em 13.6.2003 e na forma revisada em 5.3.2004.

Eng.-Agr., Ph.D., Professor, Faculdade de Agronomia da Universidade Federal do Rio Grande do Sul - UFRGS, Caixa Postal 15.100, 90001-970 Porto Alegre-RS, <ribas.vidal@ufrgs.br>; ${ }^{3}$ Eng.-Agr., M.S., UFRGS. 
conclude that EWT can be determined from density data assessed on experiments designed to test residual herbicides. Therefore, the EWT obtained are appropriate for situations requiring postemergence herbicides in areas treated with residual herbicides. The EWT of BRAPL in corn crop increases with the increase of crop prices and reduction of weed control costs; and grain price increase reduces the relative impact of weed control cost on crop profit.

Key words: residual herbicides, research method, interference, and competition.

\section{INTRODUÇÃO}

Brachiria plantaginea (BRAPL) é uma gramínea de ciclo anual com reprodução por sementes. Cresce principalmente nos periodos de primavera e verão em áreas ocupadas com culturas anuais, especialmente lavouras de milho ou soja (Häfliger \& Scholz, 1980; Kissmann, 1997). No Brasil, é uma das plantas daninhas mais freqüentes nos solos cultivados das regiões Centro e Sul e está presente em quase todos os Estados (Lorenzi, 1991). Encontra-se em $62 \%$ das áreas do Planalto do Rio Grande do Sul, sendo a gramínea com maior incidência nessa região (Bianchi, 1996). A presença desta planta daninha na lavoura pode reduzir o rendimento de grãos de milho em até 90\% (Merotto Jr. et al., 1997), podendo inviabilizar economicamente o cultivo desta cultura se o manejo for inadequado.

O conhecimento da capacidade de interferência de plantas daninhas sobre as culturas é importante na tomada de decisão para realização do controle. De posse dessa informação, conhecendo o preço do produto colhido, o custo do controle e o rendimento estimado da cultura, será possível determinar o nível de dano econômico (NDE) das plantas daninhas, ou seja, a densidade dessas cuja interferência sobre a cultura superará o custo do controle (Radosevich et al., 1997). Weaver (1991) verificou que o nível de dano econômico de Xanthium strumarium, Abutilon theophrasti ou Datura stramonium, na cultura da soja, ocorre com densidades de $1,4,2,5$ ou 0,7 plantas $\mathrm{m}^{-2}$, respectivamente.

No Brasil, a aplicação do NDE é uma prática muito difundida na tomada de decisão para controle de pragas e doenças em plantas (Siqueira et al., 1996), porém sua utilização na área de plantas daninhas ainda é restrita.
O cálculo do NDE normalmente considera que o preço da cultura, a densidade de plantas daninhas e o custo do controle são estáveis. Theisen (1998) determinou o nível de dano econômico de BRAPL na cultura de soja, fixando o preço da soja em $\mathrm{R} \$ 170 \mathrm{t}^{-1} \mathrm{e}$ o custo do controle em R $\$ 20$ ha $^{-1}$, e concluiu que, nessas condições, o controle das plantas daninhas que emergiram na cultura tornou-se economicamente viável somente a partir da densidade de 25 plantas $\mathrm{m}^{-2}$. Entretanto, sem considerar as oscilações que ocorrem nos preços dos produtos agrícolas e no custo do controle, raramente o NDE calculado em uma safra pode ser utilizado em tomadas de decisão para o controle nas safras seguintes, porque, especula-se, este nível varia com as alterações ocorridas na economia.

Muitos trabalhos realizados para determinar o NDE apresentam uma falha metodológica que também deixa incorreta sua previsão. Essa falha consiste em manter fixa a densidade de plantas daninhas, do início até o fim do ciclo da cultura. As plantas que emergem mais cedo, logo após a semeadura das culturas, são as mais competitivas (Knezevic et al., 1994; Dieleman et al., 1995; Rizzardi, 2002). Contudo, agregar esta variável para determinar o NDE tornaria os experimentos muito trabalhosos e dificultaria sua repetição em várias localidades.

Experimentos de avaliação de eficácia de controle de herbicidas residuais são realizados corriqueiramente em todo o país e, com a coleta de informações adicionais, poderiam fornecer informações valiosas para se construir um banco de dados para estabelecer os NDEs para diversas plantas daninhas e culturas. Especula-se que essas condições experimentais se aproximam da realidade do agricultor, em que ocorre fluxo continuado de plantas daninhas após a emergência da cultura. 
Os objetivos deste estudo foram avaliar a possibilidade de utilizar experimentos de eficácia de herbicidas residuais para determinar o NDE, a partir do rendimento de grãos de milho em relação à densidade de plantas de Brachiaria plantaginea que emergem após o tratamento, e avaliar o impacto do preço da cultura e do custo do controle no NDE.

\section{MATERIAL E MÉTODOS}

O experimento foi conduzido a campo, na estação de crescimento 1998/99, na Estação Experimental Agronômica da Universidade Federal do Rio Grande do Sul (EEA/UFRGS), em Eldorado do Sul-RS. O solo da área experimental é classificado como Argissolo Vermelho Distrófico típico, com $380 \mathrm{~g} \mathrm{~kg}^{-1}$ de argila, $24 \mathrm{~g} \mathrm{~kg}^{-1}$ de matéria orgânica, $5 \mathrm{mg} \mathrm{dm}^{-3} \mathrm{de}$ fósforo, $140 \mathrm{mg} \mathrm{dm}^{-3}$ de potássio e $\mathrm{pH}$ de 5,5.

O milho, híbrido AG 5011, foi implantado no dia 8 de outubro de 1998, no sistema de semeadura direta, em sucessão à cultura de aveia preta. A adubação do milho foi feita na linha de semeadura com $600 \mathrm{~kg} \mathrm{ha}^{-1}$ da fórmula NPK 5-20-20. Realizou-se adubação nitrogenada de cobertura com 100 e $150 \mathrm{~kg}$ de $\mathrm{N} \mathrm{ha}^{-1}$, quando o milho se apresentava nos estádios $\mathrm{V}_{4}$ e $\mathrm{V}_{8}$ (4 e 8 folhas expandidas, respectivamente).

As densidades de BRAPL foram obtidas com dez tratamentos herbicidas residuais, três testemunhas sem controle e duas testemunhas capinadas durante todo o ciclo da cultura, em quatro repetições, conforme descrito por Spader \& Vidal (2000). Esses tratamentos possibilitaram a emergência de plantas de BRAPL em diferentes densidades, nas 60 parcelas do experimento, proporcionando vários níveis de interferência sobre a cultura do milho.

A área útil das parcelas foi de 8,0 x 1,6 m, contendo duas fileiras de milho, espaçadas de 0,80 m e com 5,6 plantas por metro na fileira, perfazendo população de 70.000 plantas de milho ha ${ }^{-1}$ após desbaste, realizado aos dez dias após a emergência (DAE). O controle de plantas daninhas dicotiledôneas foi realizado com atrazine $\left(2,0 \mathrm{~kg} \mathrm{ha}^{-1}\right)$ em toda a área do experimento, em pré-emergência. Efetuou-se irrigação por aspersão nos períodos em que a precipitação pluvial foi insuficiente para suprir a exigência da cultura, até o estádio de maturação fisiológica do milho.

Avaliaram-se a densidade de BRAPL (número de plantas $\mathrm{m}^{-2}$ ) aos 10, 20, 30, $40 \mathrm{e}$ 50 DAE e o rendimento de grãos do milho. A densidade de plantas de BRAPL foi avaliada em cada unidade experimental, utilizando-se quadrado, medindo 0,5 m de lado, posicionado em dois locais marcados dentro da área útil da parcela, para contagem das plantas daninhas presentes em cada época de avaliação. Após a colheita do milho, foram feitas análises de regressão entre densidade de plantas de BRAPL e rendimento de grãos do milho. Essas regressões foram feitas com auxílio do programa computacional "Origin”, que calcula por teste quiquadrado a significância da equação. As curvas ajustadas foram segmentadas em linhas retas, para se obter a declividade de cada segmento linear. A intercepção no eixo y (a) e as declividades (D) do primeiro segmento das curvas de densidade foram utilizadas para estimar o NDE da BRAPL no milho, conforme a equação 1 .

$$
\left.\mathrm{NDE}=\mathrm{CC} /\left[10.000 * \mathrm{D} / \mathrm{a}^{*}(\mathrm{P} / 1.000)\right] \quad \text { (eq. } 1\right)
$$

Para cálculo do NDE, considerou-se o preço do milho $(\mathrm{P})$ variando entre $\mathrm{R} \$ 100$ e $300 \mathrm{t}^{-1}$, e o custo do controle (CC), entre R $\$ 20$ e 60 ha $^{-1}$. As estimativas foram feitas tomando-se como base o rendimento da cultura de $10.000 \mathrm{~kg} \mathrm{ha}^{-1}$, porém o cálculo poderá ser realizado para qualquer estimativa de rendimento, bastando substituir o valor correspondente na equação 1 .

\section{RESULTADOS E DISCUSSÃO}

A resposta da regressão entre densidade de BRAPL e rendimento de grãos de milho ajustou curvas do tipo exponencial decrescente nas avaliações realizadas aos 10 e $20 \mathrm{DAE}$ e curvas do tipo sigmoidal aos 30, 40 e 50 DAE (Tabela 1). A diferença de resposta em função da época de avaliação da densidade de BRAPL é atribuída ao incremento da infestação das plantas daninhas com o decorrer do tempo. A presença de plantas de BRAPL no início do período crítico (20 DAE) de competição do milho pode resultar em perdas elevadas no rendimento de grãos da cultura, caso estas plantas não sejam controladas. Verifica-se que, quando a densidade de BRAPL foi inferior a 
24 plantas $\mathrm{m}^{-2}$ (ponto de inflexão da curva), cada planta reduziu o rendimento de grãos de milho em $288 \mathrm{~kg} \mathrm{ha}^{-1}$. No entanto, quando a densidade de BRAPL foi superior a 24 plantas $\mathrm{m}^{-2}$, verificou-se que cada planta de BRAPL teve menor impacto no rendimento de grãos de milho, ficando em $17 \mathrm{~kg} \mathrm{ha}^{-1}$ (Figura 1). Entretanto, deve-se considerar que a perda decorrente do aumento do número de indivíduos tem efeito cumulativo e que 24 plantas $\mathrm{m}^{-2}$ de BRAPL já provocaram perdas de $60 \%$ no rendimento de grãos do milho (Figura 1).

A segmentação da curva obtida pela regressão entre densidade de BRAPL aos 50 DAE (final do período crítico) e rendimento de grãos de milho (Figura 2) indica que, em densidade de BRAPL inferior a 25 plantas $\mathrm{m}^{-2}$ (primeiro ponto de inflexão da sigmóide), cada planta reduziu o rendimento de grãos em $43 \mathrm{~kg} \mathrm{ha}^{-1}$. $\mathrm{Na}$ densidade compreendida entre 25 e 83 plantas $\mathrm{m}^{-2}$ (segundo ponto de inflexão da sigmóide), o impacto de cada planta sobre o rendimento da cultura foi mais pronunciado, resultando em perdas de $110 \mathrm{~kg} \mathrm{ha}^{-1}$. Em densidades superiores a 83 individuos $\mathrm{m}^{-2}$, cada planta adicional incrementou a perda de rendimento de grãos de milho em apenas $9 \mathrm{~kg} \mathrm{ha-1.}$

A variação da resposta da cultura conforme a densidade pode ter ocorrido em função do efeito dos herbicidas ou dos efeitos da época de ocorrência das plantas daninhas. De fato, é possivel que os resíduos de herbicidas nestas plantas que ocorreram no início do ciclo da cultura tenham prejudicado o desenvolvimento de BRAPL. Além disso, a baixa infestação observada no início do período crítico de prevenção

Tabela 1 - Equações de regressão entre densidade de Brachiaria plantaginea e rendimento de grãos de milho em cinco épocas após a emergência da cultura. Eldorado do Sul-RS, 1998/99

\begin{tabular}{|c|c|c|}
\hline DAE & Equação & $\chi^{2}$ \\
\hline 10 & $Y=1092+7961 e^{(-x / 6,44)}$ & $1,0 \cdot 10^{6 * *}$ \\
\hline 20 & $\mathrm{Y}=1250+8334 \mathrm{e}^{(-\mathrm{x} / 2 \overline{0}, 1)}$ & $1,0 \cdot 10^{6} * *$ \\
\hline 30 & $\mathrm{Y}=(11765-1365) /\{1+\operatorname{EXP}[(\mathrm{X}-23,3) / 17]\}+1365$ & $1,0 \cdot 10^{6 * *}$ \\
\hline 40 & $\mathrm{Y}=(10915-1442) /\{1+\operatorname{EXP}[(\mathrm{X}-36,6) / 18,8]\}+1442$ & $7,0 \cdot 10^{5 * *}$ \\
\hline 50 & $\mathrm{Y}=(10082-1869) /\{1+\mathrm{EXP}[(\mathrm{X}-50) / 15]\}+1869$ & $6,1 \cdot 10^{5 * *}$ \\
\hline
\end{tabular}

** Equação significativa $(\mathrm{P}<0,01)$, pelo teste $\chi^{2}$.

Y: rendimento de grãos de milho $\left(\mathrm{kg} \mathrm{ha}^{-1}\right)$; X: densidade de plantas de Brachiaria plantaginea (plantas $\left.\mathrm{m}^{-2}\right)$; e DAE: dias após a emergência da cultura.



Figura 1 - Rendimento de grãos de milho em função da densidade de Brachiaria plantaginea (BRAPL) aos 20 dias após a emergência da cultura ( $\mathrm{n}=$ número de dados incluídos na segmentação da curva). Eldorado do Sul-RS, 1998/99.

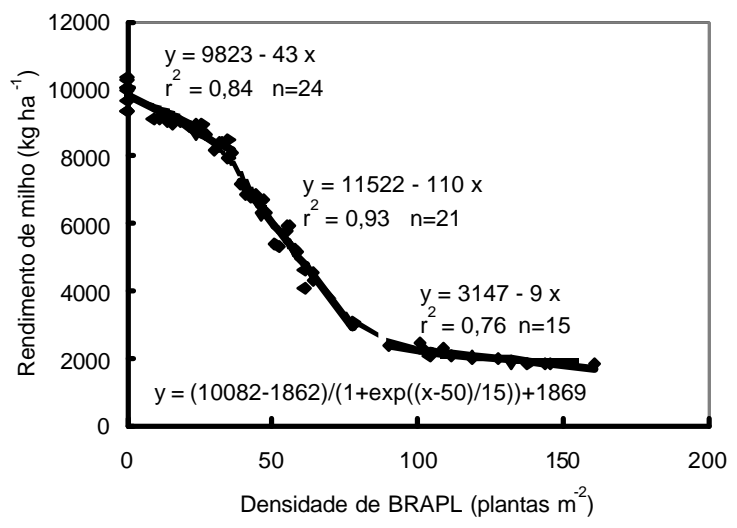

Figura 2 - Rendimento de grãos de milho em função da densidade de Brachiaria plantaginea (BRAPL) aos 50 dias após a emergência da cultura ( $\mathrm{n}=$ número de dados incluídos na segmentação da curva). Eldorado do Sul-RS, 1998/99. 
da interferência, aliada à alta disponibilidade de recursos do meio, pode ter favorecido a cultura, possibilitando-lhe maior crescimento inicial e melhor aproveitamento da radiação solar em relação às plantas danhinhas. O aumento da densidade de BRAPL com o decorrer do tempo intensificou a capacidade competitiva desta, o que pode explicar a mudança nas curvas de resposta verificadas após 20 DAE.

A diferença de resposta obtida entre as avaliações realizadas aos 20 e 50 DAE sugere que, quanto mais cedo ocorre a emergência de plantas daninhas, maior é o seu impacto sobre o rendimento do milho. Por exemplo, quando as plantas cultivadas e daninhas emergiram na mesma época, Amaranthus retroflexus, na densidade de duas plantas $\mathrm{m}^{-2}$, reduziu o rendimento de grãos de soja em 14\%; contudo, quando as plantas daninhas emergiram a partir do estádio de três folhas $\left(\mathrm{V}_{3}\right)$ da soja, não afetaram o rendimento da cultura a ponto de compensar economicamente a realização do controle (Dieleman et al., 1995). Vangessel \& Westra (1997) verificaram que a cultura do feijão apresentou maior rendimento de grãos e maior retorno econômico quando Anoda cristata foi controlada no momento em que a cultura estava no estádio de desenvolvimento $\mathrm{V}_{1}$ e as plantas daninhas com o máximo de duas folhas do que quando o controle foi realizado com a cultura no estádio $\mathrm{V}_{3}$, com as plantas daninhas apresentando entre quatro e cinco folhas.

As plantas daninhas cuja emergência ocorre ao mesmo tempo que a cultura, ou logo após, podem usufruir de maior quantidade de recursos disponíveis no meio, resultando em maior acúmulo de matéria seca e maior capacidade competitiva com a cultura (Rizzardi, 2002). Nas primeiras semanas após a emergência, o milho intercepta pequena quantidade da radiação luminosa incidente sobre a lavoura, pois sua área foliar ainda é pouco expressiva e a densidade de plantas é insuficiente para cobrir toda a superfície do solo. Assim, grande quantidade da energia luminosa que chega até a lavoura pode ser aproveitada pelas plantas daninhas. À medida que a cultura se desenvolve, aumentam a captação de luz e o sombreamento da área, tornando-a mais competitiva com as plantas daninhas, principalmente aquelas que emergirem após esse período.
O nivel de dano econômico (NDE) de BRAPL em milho, com base na densidade determinada no início do período crítico de prevenção da interferência (20 DAE) e considerando o nível de produtividade de $10 \mathrm{t} \mathrm{ha}^{-1}$, variou entre 0,2 e 2,0 plantas $\mathrm{m}^{-2}$, dependendo do preço do milho e do custo de controle (Figura 3). Considerando-se que o preço do milho tradicionalmente tem sido de $\mathrm{R} \$ 150 \mathrm{t}^{-1}$ e que o custo do controle de plantas daninhas tem sido de aproximadamente $\mathrm{R} \$ 30 \mathrm{ha}^{-1}$, verificou-se que o nível de dano econômico de BRAPL foi de 0,7 planta $\mathrm{m}^{-2}$ (Figura 3).

Caso o controle não seja realizado, ou se for incompleto, o rendimento de grãos da cultura não será afetado quando ao término do período crítico de interferência (50 DAE) a densidade de BRAPL variar entre 1,5 e 13 plantas $\mathrm{m}^{-2}$, dependendo do preço do milho e do custo do controle (Figura 4). Deve-se salientar que as plantas não controladas abastecerão o banco de sementes no solo, o que poderá ocasionar prejuízos nas safras seguintes.

Os NDEs relatados neste trabalho são adequados a situações em que se deseja decidir por aplicações em pós-emergência onde anteriormente foram aplicados herbicidas residuais, analogamente à metodologia utilizada no experimento. Em situações nas quais o controle de BRAPL não tenha sido realizado com herbicidas residuais, a emergência das plantas daninhas pode se iniciar junto com a cultura. Assim, aos 20 DAE, a infestação da área com BRAPL deverá estar além dos NDEs relatados para justificar a utilização de medidas de controle em pós-emergência.

Os resultados obtidos neste trabalho indicam a possibilidade de utilizar experimentos de eficácia de herbicidas residuais para determinar o NDE nas culturas. Especula-se que, quando a decisão pelo controle de plantas daninhas for tomada no início do período crítico (20 DAE), ele poderia ser feito com herbicidas que possuam atividade foliar e com poder residual, eliminando as plantas daninhas resistentes e prevenindo o surgimento de outras durante todo o período crítico de prevenção da interferência. As figuras com NDE (Figuras 3 e 4) sugerem que estratégias de baixo custo de controle podem ser utilizadas com menores densidades de plantas daninhas, com o benefício de haver menor produção de sementes e, 
conseqüentemente, menor crescimento do banco de sementes no solo. Além disso, observa-se que, quando o preço da cultura se eleva, o custo do controle tem menor impacto no retorno econômico após o controle (Figuras 3 e 4).

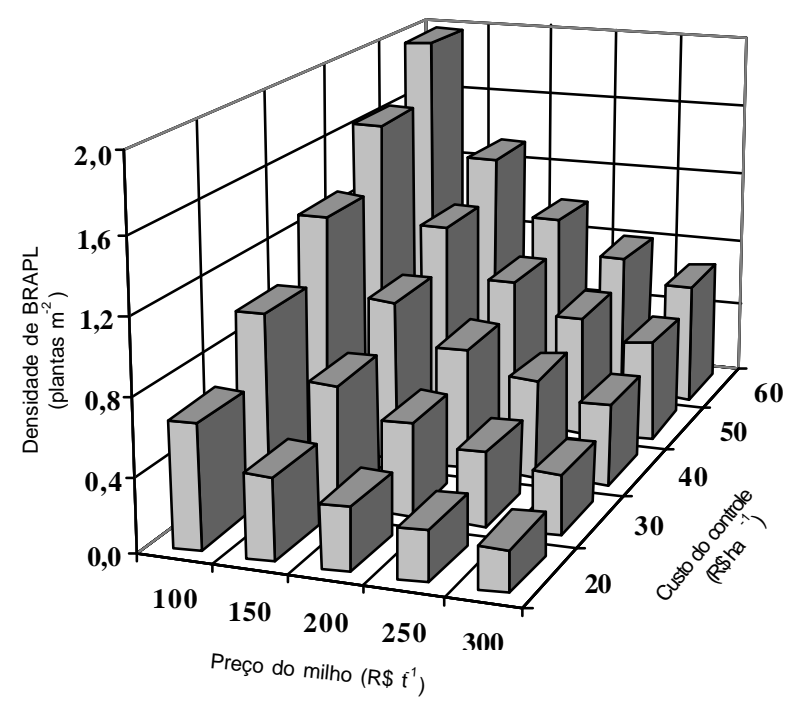

Figura 3 - Nível de dano econômico na cultura do milho com base na densidade de plantas de Brachiaria plantaginea (BRAPL) aos 20 dias após a emergência da cultura. Eldorado do Sul-RS, 1998/99.

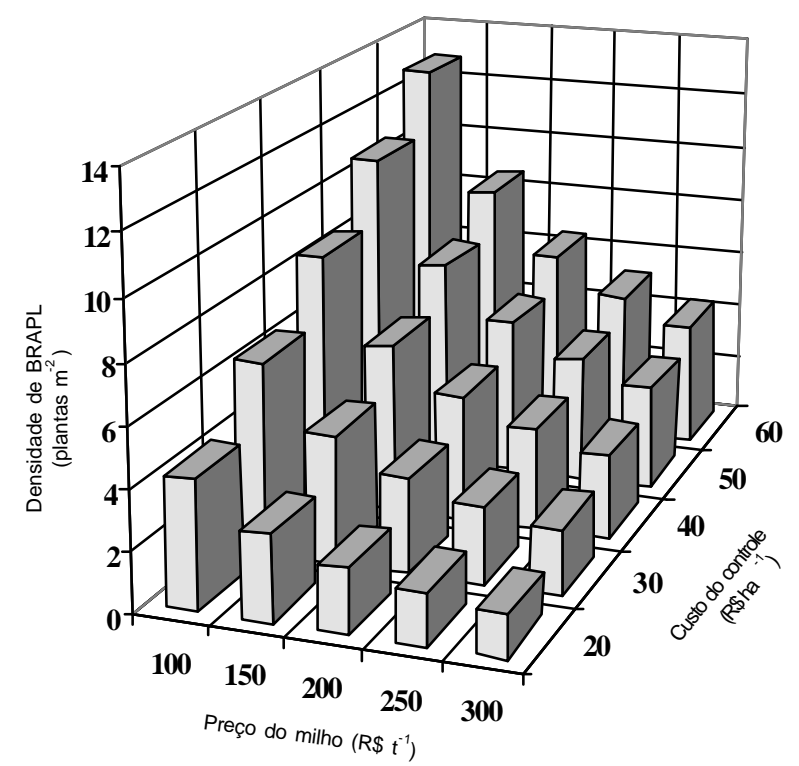

Figura 4 - Nível de dano econômico na cultura do milho com base na densidade de plantas de Brachiaria plantaginea (BRAPL) aos 50 dias após a emergência. Eldorado do SulRS, 1998/99.
Os resultados deste trabalho possibilitam afirmar que a densidade de plantas de Brachiaria plantaginea aumenta com o decorrer do tempo; o nível de dano econômico de Brachiaria plantaginea em milho pode ser estabelecido com dados de densidade de plantas daninhas determinados em experimentos para teste de herbicidas residuais; o nível de dano econômico de Brachiaria plantaginea em milho aumenta à medida que diminui o preço desta cultura e aumenta o custo do controle; e o aumento do preço do milho reduz o impacto do custo de controle de Brachiaria plantaginea no retorno econômico da cultura.

\section{LITERATURA CITADA}

BIANCHI, M. A. Programa de difusão do manejo integrado de plantas daninhas em soja. In: REUNIÃO DE PESQUISA DE SOJA DA REGIÃo SUL, 23., Porto Alegre. Ata e resumos. Porto Alegre: Universidade Federal do Rio Grande do Sul, 1996. p. 125.

DIELEMAN, A. et al. Empirical models of pigweed (Amaranthus spp.) interference in soybean (Glycine max). Weed Sci., v. 43, n. 4, p. 612-618, 1995.

HÄFLIGER, E.; SCHOLZ, H. Grass weeds 1: weeds of subfamily Panicoidea. Basle, Switzerland: Ciba Geigy, 1980. $142 \mathrm{p}$.

KISSMANN, K. G. Plantas infestantes e nocivas. São Paulo: BASF, 1997. 824 p

KNEZEVIC, S. Z.; WEISE, S. F.; SWANTON, C. J. Interference of redroot pigweed (Amaranthus retroflexus) in corn (Zea mays). Weed Sci., v. 42, n. 3, p. 568-573, 1994.

LORENZI, H. Plantas daninhas do Brasil: terrestres, aquáticas, parasitas, tóxicas e medicinais. 2.ed. Nova Odessa: Plantarum, 1991. 340 p.

MEROTTO Jr., A. et al. Aumento da população de plantas e uso de herbicidas no controle de plantas daninhas em milho. Planta Daninha, v. 15, n. 2, p. 141-151, 1997.

RADOSEVICH, S. R.; HOLT, J. S.; GHERSA, C. Weed ecology: implications for vegetation management. 2.ed. New York: Wiley \& Sons, 1997. 588 p.

RIZZARDI, M. A. Nível de dano econômico para tomada de decisão no controle de picão-preto (Bidens spp.) e guanxuma (Sida rhombifolia $\mathbf{L}$.) na cultura da soja. 2002. $176 \mathrm{f}$. Tese (Doutorado em Fitotecnia - Plantas de Lavoura) - Universidade Federal do Rio Grande do Sul, Porto Alegre, 2002. 
SIQUEIRA, H. A. A.; CAVALCANTE, T. R. M.;

BARRETO, M. P. Flutuação populacional de brocas da bananeira e a ocorrência natural de Beauveria bassiana em Viçosa, MG. In: CONGRESSO BRASILEIRO DE

FRUTICULTURA, 16., 1996, Curitiba. Resumos... Curitiba: Sociedade Brasileira de Fruticultura, 1996. v. 1. p. 66.

SPADER, V.; VIDAL, R. A. Eficácia de herbicidas graminicidas aplicados em pré-emergência no sistema de semeadura direta do milho. Planta Daninha, v. 18, n. 2, p. 373-380, 2000.
THEISEN, G. Influência de aveia preta em papuã (Brachiaria plantaginea (Link) Hitchc.) e seu impacto em soja. 1998. 87 f. Dissertação (Mestrado em Fitotecnia) Universidade Federal do Rio Grande do Sul, 1998.

WANGESSEL, M.; WESTRA, P. Economics and efficacy of postemergence spurred anoda (Anoda cristata) control in pinto beans (Phaseolus vulgaris). Weed Technol., v. 11, n. 2, p. 329-334, 1997.

WEAVER, S. E. Size-dependent economic thresholds for three broadleaf weed species in soybeans. Weed Technol., v. 5 , n. 4 , p. 674-679, 1991. 